\section{A metáfora museográfica da organização social Bororo no Museu das Culturas Dom Bosco}

\author{
Carla Fabiana Costa Calarge*
}

Resumo: Durante o processo de reestruturação do Museu Dom Bosco, que passaria a se chamar Museu das Culturas Dom Bosco, um dos objetivos da equipe era conceber uma exposição museográfica da Cultura Bororo, a partir de um acervo de referência internacional pela sua riqueza e diversidade. O desafio estava em evidenciar os elementos simbólicos dessa etnia na museografia. A exposição aqui é tomada como uma metáfora da aldeia tradicional, portanto circular, dividida em duas metades, Tugarege e Ecerae. Cada metade é dividida em quatro clãs, simbolizados por vitrines verticais que abrigam objetos separados por direito de uso. O círculo da aldeia em si é formado por vitrines horizontais contendo objetos específicos de caça, pesca, e da vida cotidiana de mulheres homens e crianças. A vitrine central, que divide o círculo de leste, Itubore, a oeste, bakoro, contém objetos de uso ritual do rito de nominação e o fúnebre. O objetivo desse texto está em revisar aspectos da organização social bororo a partir da museografia da exposição bororo no Museu das Culturas Dom Bosco em Campo Grande.

Palavras-chave: Bororo; organização social; etnologia; museu; museografia.

A partir de 2003, se iniciou o processo de reestruturação do Museu Dom Bosco (MDB), que, depois de sua reinauguração, passaria a se chamar Museu das Culturas Dom Bosco (MCDB). O projeto incluía um novo espaço mais amplo (quatro vezes maior que o anterior) e uma completa reformulação da proposta museográfica tradicional.

Do ponto de vista museográfico, a exposição deveria oferecer ao visitante, não apenas aspetos práticos do modo de vida tradicional dos indígenas, mas efetivamente contextualizar a coleção e comunicar a relação daqueles objetos e sua estreita relação com o sagrado. Em outras palavras, o objetivo dos museógrafos era expor esses objetos de forma que eles pudessem ter significado evidente para os próprios bororos e
* Graduada em Ciências Sociais (201 1) pela Universidade Federal de Mato Grosso do Sul (UFMS), em Comunicação Social (2008) pela Universidade Católica Dom Bosco (UCDB) e Mestre em Antropologia pelo Programa de Pós-Graduação em Antropologia (PPGAnt), com área de concentração em Antropologia Sociocultural da Universidade Federal da Grande Dourados (UFGD). Atualmente é responsável pela Coleção de Etnologia do Museu das Culturas Dom Bosco. E-mail: carla.calarge@gmail.com

\author{
Tellus, ano 13, n. 25, p. 217-229, jul./dez. 2013 \\ Campo Grande, MS
}


pesquisadores, além de evidenciar a profundidade simbólica daquelas peças para o público cotidiano do museu.

A exposição da etnia Bororo no Museu das Culturas Dom Bosco é uma metáfora da aldeia tradicional e circular (Figura 1). O espaço é dividido em duas metades, correspondentes às metades tugarege e ecerae. Cada metade é dividida em quatro clãs, simbolizados por vitrines verticais que abrigam objetos separados por direito de uso (Figura 2). Refiro-me a ela como uma "metáfora", porque se trata de uma representação do modelo original, passível de comparação.

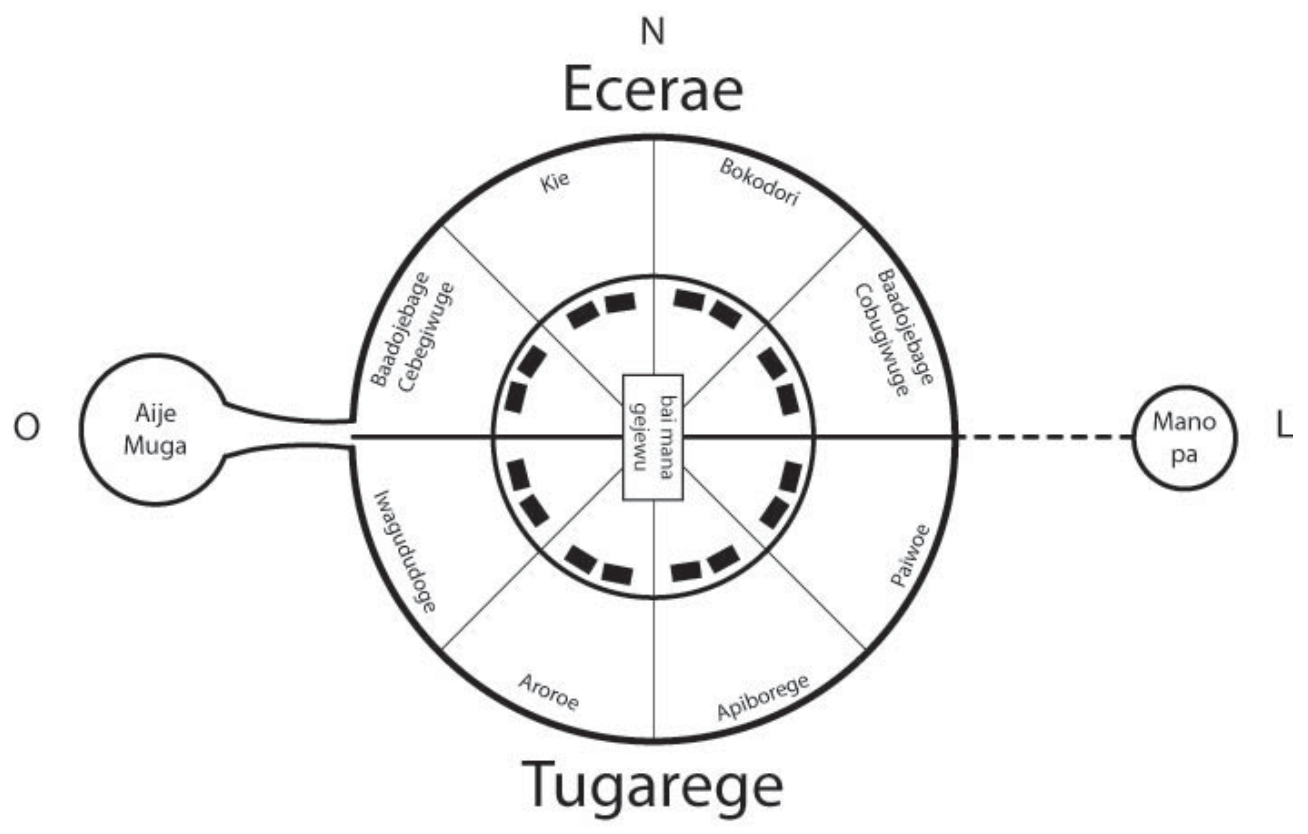

$\mathrm{S}$

Figura 1 - Aldeia Bororo e suas Divisões ${ }^{1}$

\footnotetext{
1 "Na metade dos Tugarege, por causas ignoradas, o clã dos Iwagududoge interpelou-se com no clã dos Aroroe o qual ficou parte ao leste, com os membros do clã Aroroe Cobugiwuge e do sub-clã dos Aroror Boe E-iadadawuge, e parte a oeste, com os membros do sub-clã dos Aroroe Cebegiwuge. Esse clã, porém, embora materialmente dividido, não forma dois clãs distintos, mas conserva sua integridade" (ALBISETTI; VENTURELLI, 1962, p. 438). Isso justifica a representação gráfica diferente da apresentada, de fato essa é a que melhor se aproxima da exposição museográfica utilizada como referência.
} 


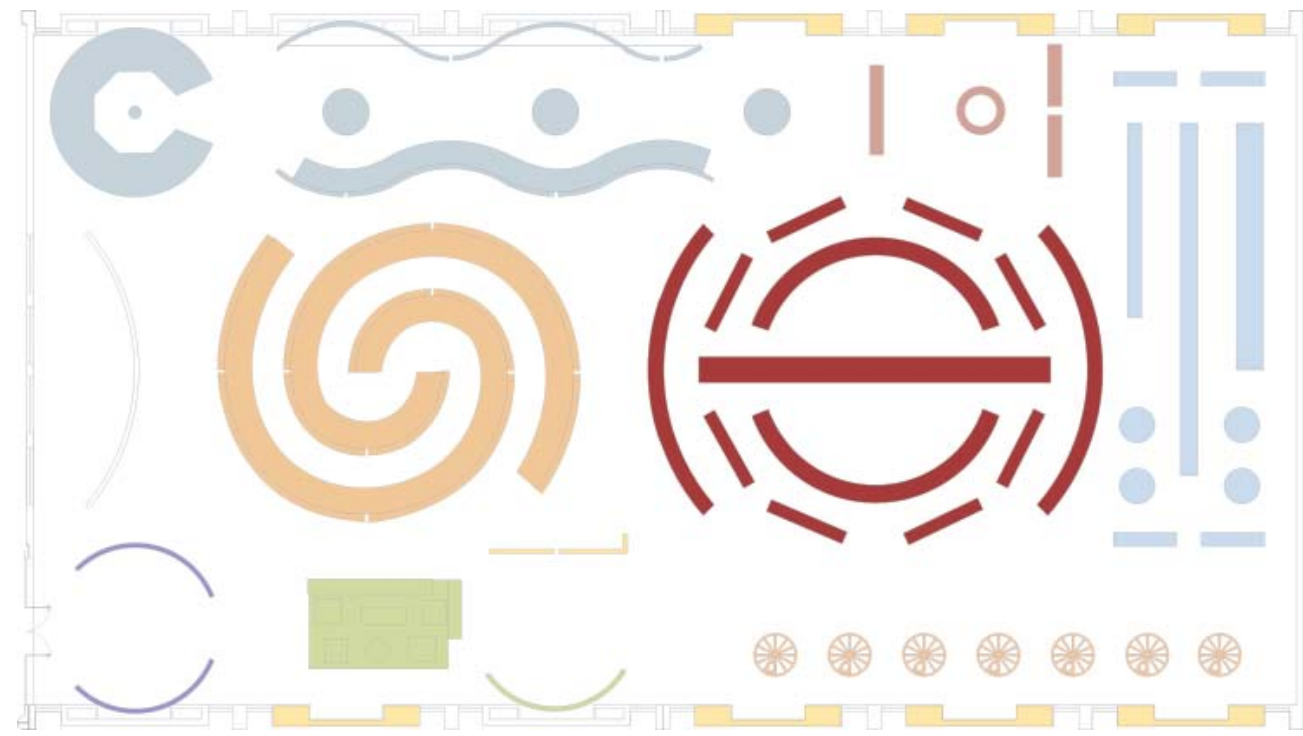

Figura 2 - Diagrama da Exposição do Museu das Culturas Dom Bosco (destaque em vermelho a exposição Bororo).

O círculo da aldeia em si (bai-doge) é formado por vitrines horizontais contendo objetos específicos de caça, pesca, e da vida cotidiana de mulheres, homens e crianças. A vitrine central, também no chão, marca o círculo de leste, itubore, a oeste, bakoro, contém objetos de uso ritual do rito de nominação e o fúnebre. A forma da parede que delimita a exposição a leste e oeste também faz referência às duas clareiras aije muga e mano PA (Figura 3).

O bai-doge (bai choupana e doge sufixo do plural) é o traçado formado pelas casas ao redor da aldeia. No Museu das Culturas Dom Bosco, estão dispostos objetos de uso cotidiano feminino, tais como cerâmicas (ária, ruwóbo e póri), abanicos de cordéis que podem ser como bandejas (baku, kodo o-kóre, parikiboto), esteiras (beto), cestas de vários tipos (kodo). Além de arcos, flechas, arpões, que são objetos de uso cotidiano masculino. Brinquedos, como bonecas, petecas, entre outros, de uso das crianças (chamados genericamente de boe ewoada).

Os bororos dividem-se em clãs e sub-clãs. As pessoas tornam-se membros das metades e dos clãs por descendência matrilinear. A escolha do marido ou da esposa é baseada em regras prescritivas, por exemplo: as tradições determinam que, nos agrupamentos, homens e mulheres tugarege casem-se com mulheres e homens ecerae. 


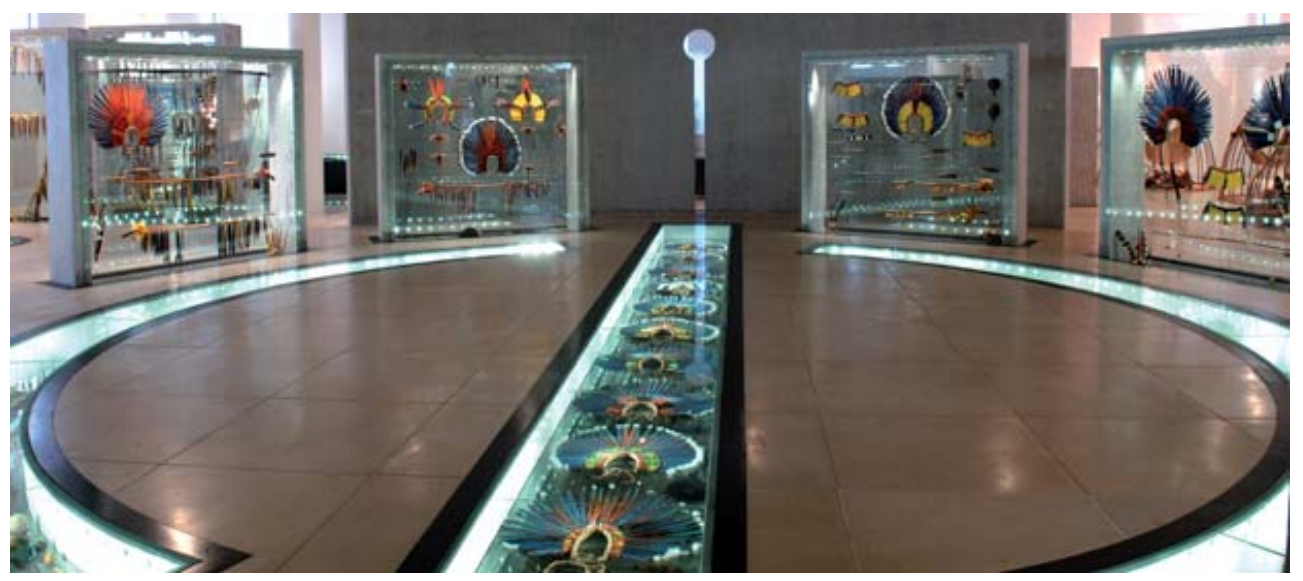

Figura 3 - Visão geral da exposição Bororo no Museu das Culturas Dom Bosco (Foto do Arquivo MCDB)

Os clãs se distinguem pela posição que ocupam na hierarquia social por emblemas, privilégios, tabus relativos à técnica e ao estilo dos objetos manufaturados e, finalmente, por cerimônias, cantos e nomes próprios que são atribuídos a cada um. No Museu das Culturas Dom Bosco, os objetivos relativos a cada clã estão devidamente apresentados nas vitrines que os representam.

Observamos na figura 5, por exemplo, a vitrine pertencente ao clã dos Bokodori, ou clã do tatu-canastra, composta por peças confeccionadas por este clã. Estão lá presentes principalmente os adornos com penas de araras vermelhas e a rede de pesca. Há vários objetos que utilizam as unhas e ossos do tatu-canastra. São expressamente os mitos que fundam privilégios de uso de técnica e matérias-primas. De modo geral, os objetos são caracterizados de uma maneira que seja possível identificar o clã e o sub-clã do proprietário. Isso se dá pela utilização de certas plumas ou cores de plumas, na disposição das mesmas, na execução de certos trabalhos decorativos, entre outros.

Na vitrine mencionada, do clã Bokodori, o pariko², por exemplo, possui predominantemente penas de arara vermelha que são cortadas de forma a deixar a peça mais estreita e alongada, seu nome tradicional é pariko akurararéu e faz referência ao akurara peixe pacu. Esse objeto deve ser entendido como "diadema curto e largo como o peixe pacu". Outro exemplo que podemos tomar, na vitrine do clã Aroroe (Figura 10), agora da metade tugarege, o pariko dos aroroe cobugiwuge, que ocupa o centro da vitrine, é chamado u-uruguréu, e sua tradução literal "diademas com plumas vermelhas" e possui detalhes de plumas pretas de mutum(ALBISETTI; VENTURELLI, 1962, p. 415-418).

\footnotetext{
${ }^{2}$ Pariko é o nome na língua Bororo para as diademas plumárias que são o adorno que mais representa o povo bororo, é também por ele que essa etnia foi chamada "coroados".
} 


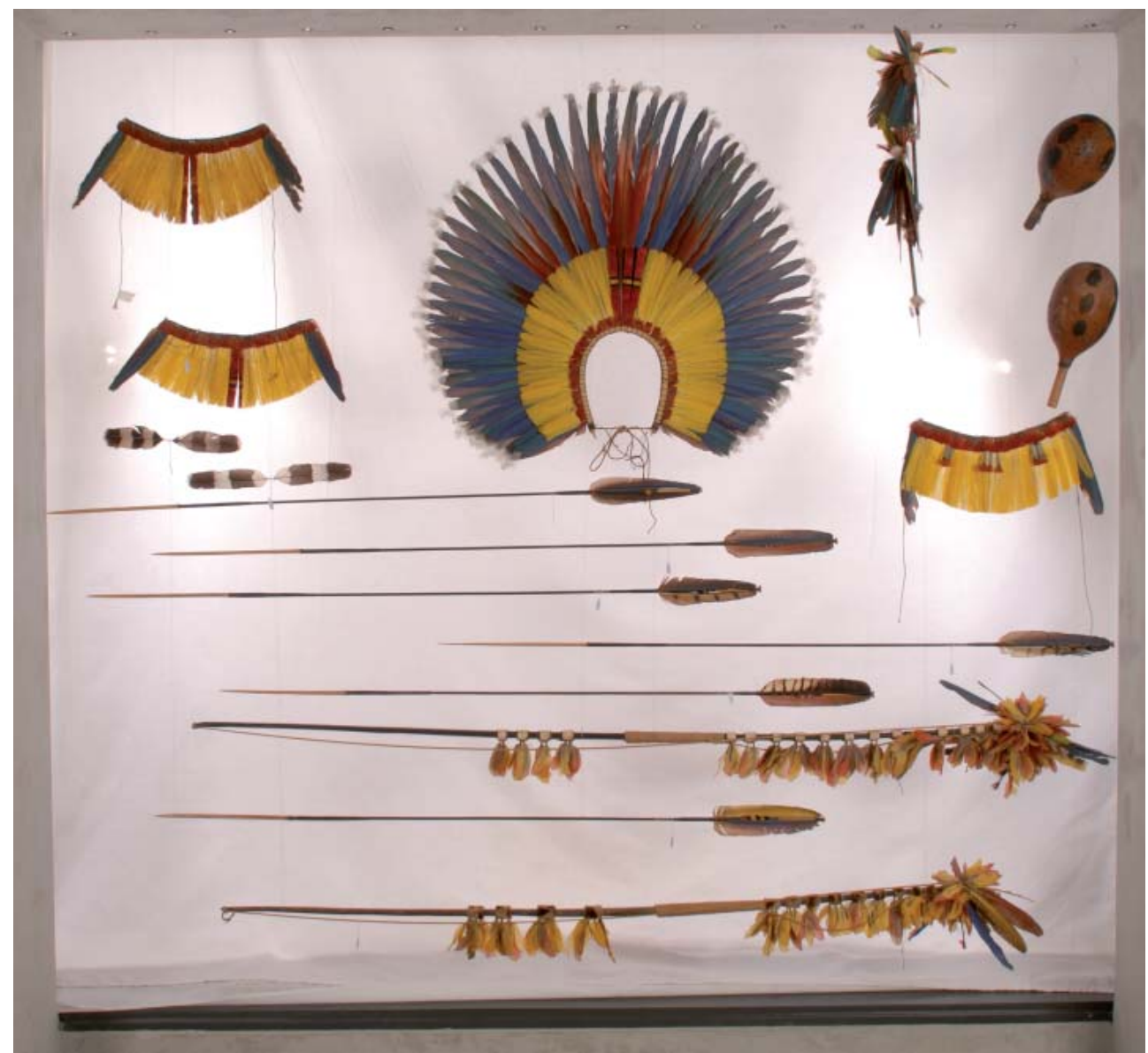

Figura 4 - Vitrine do clã Baadojebage Cebegiwuge (Metade Ecerae), durante a montagem 


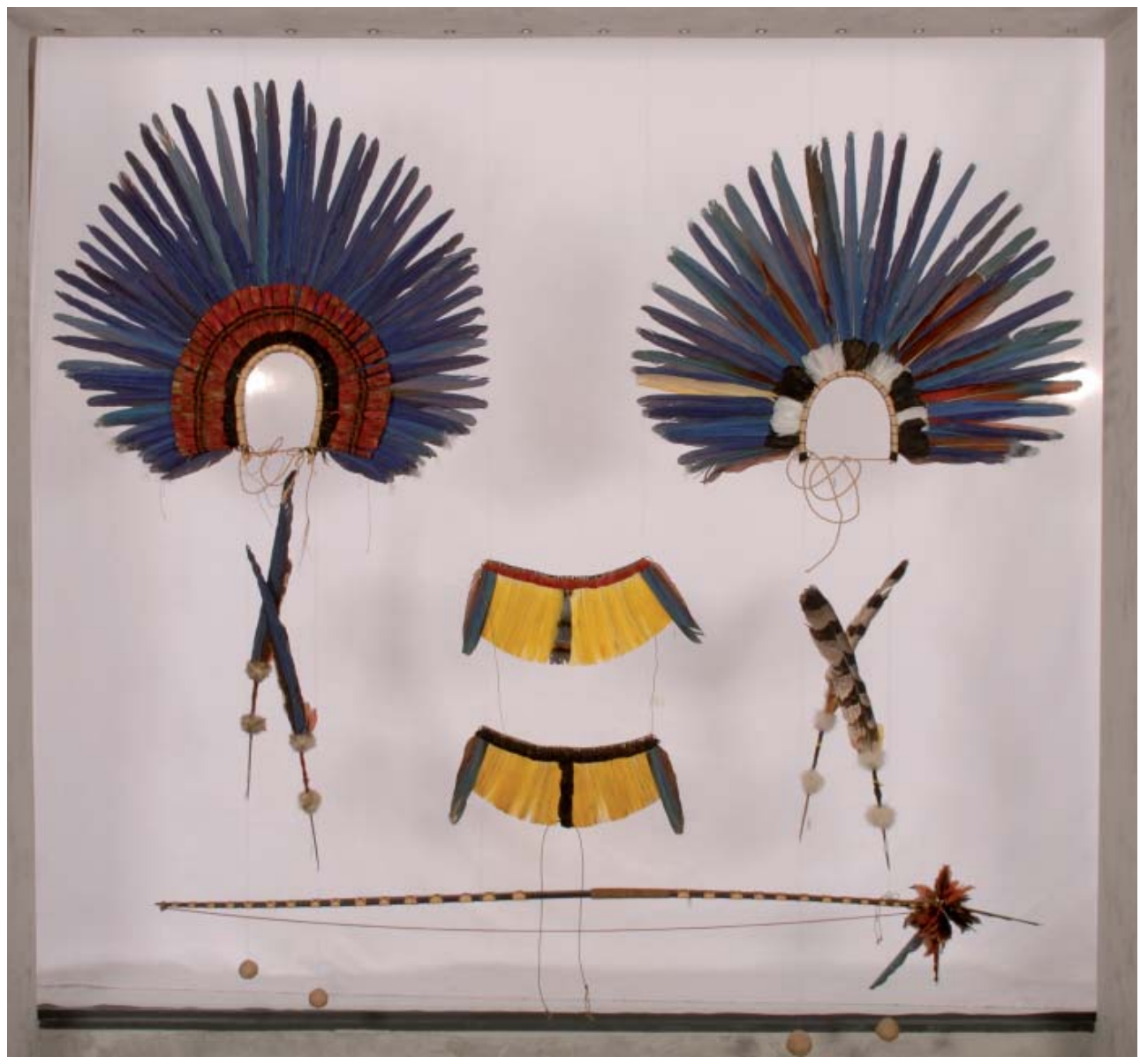

Figura 5 - Vitrine do clã Kie (Metade Ecerae), durante a montagem 


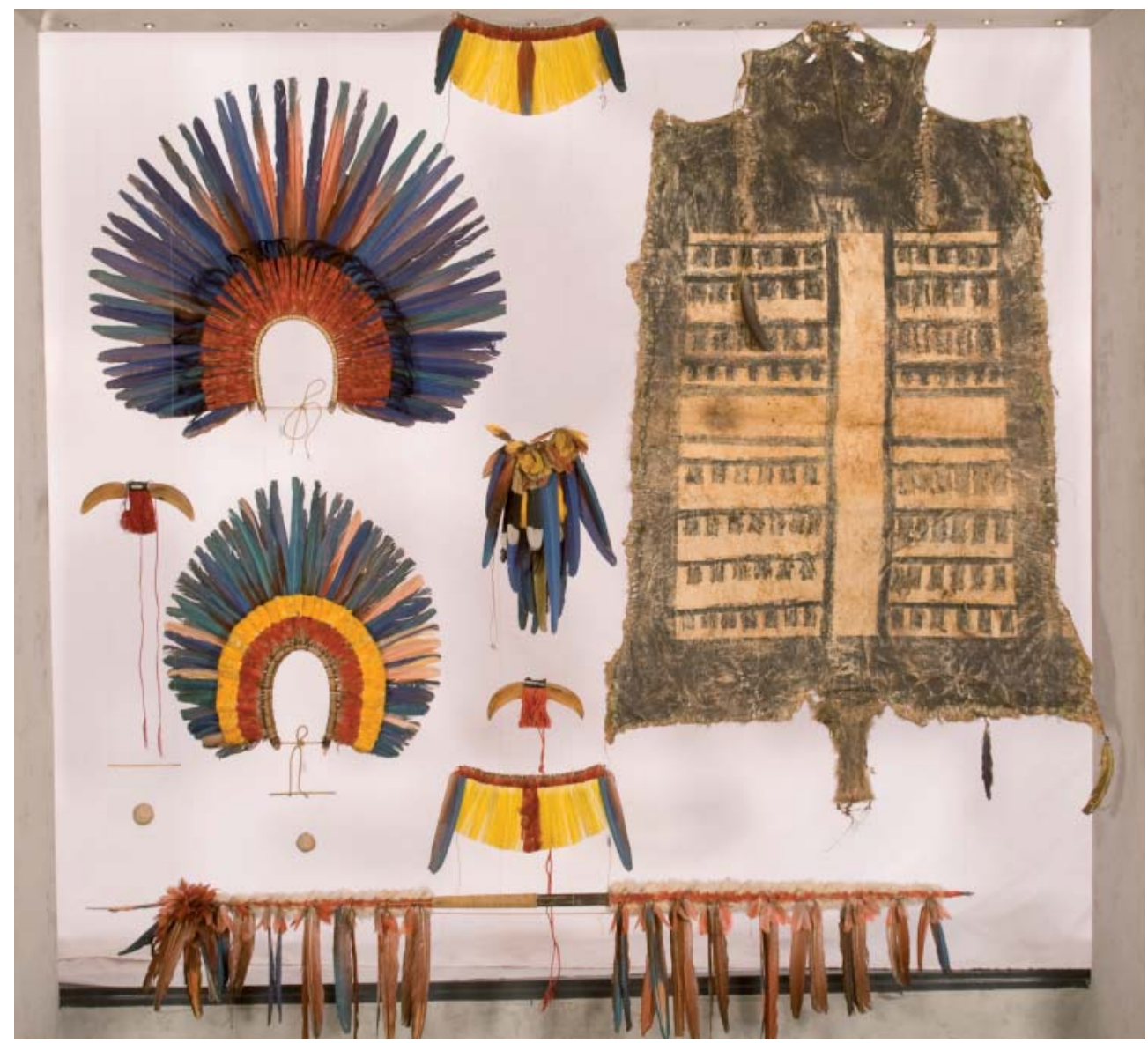

Figura 6 - Vitrine do clã Bokodori (Metade Ecerae), durante a montagem 


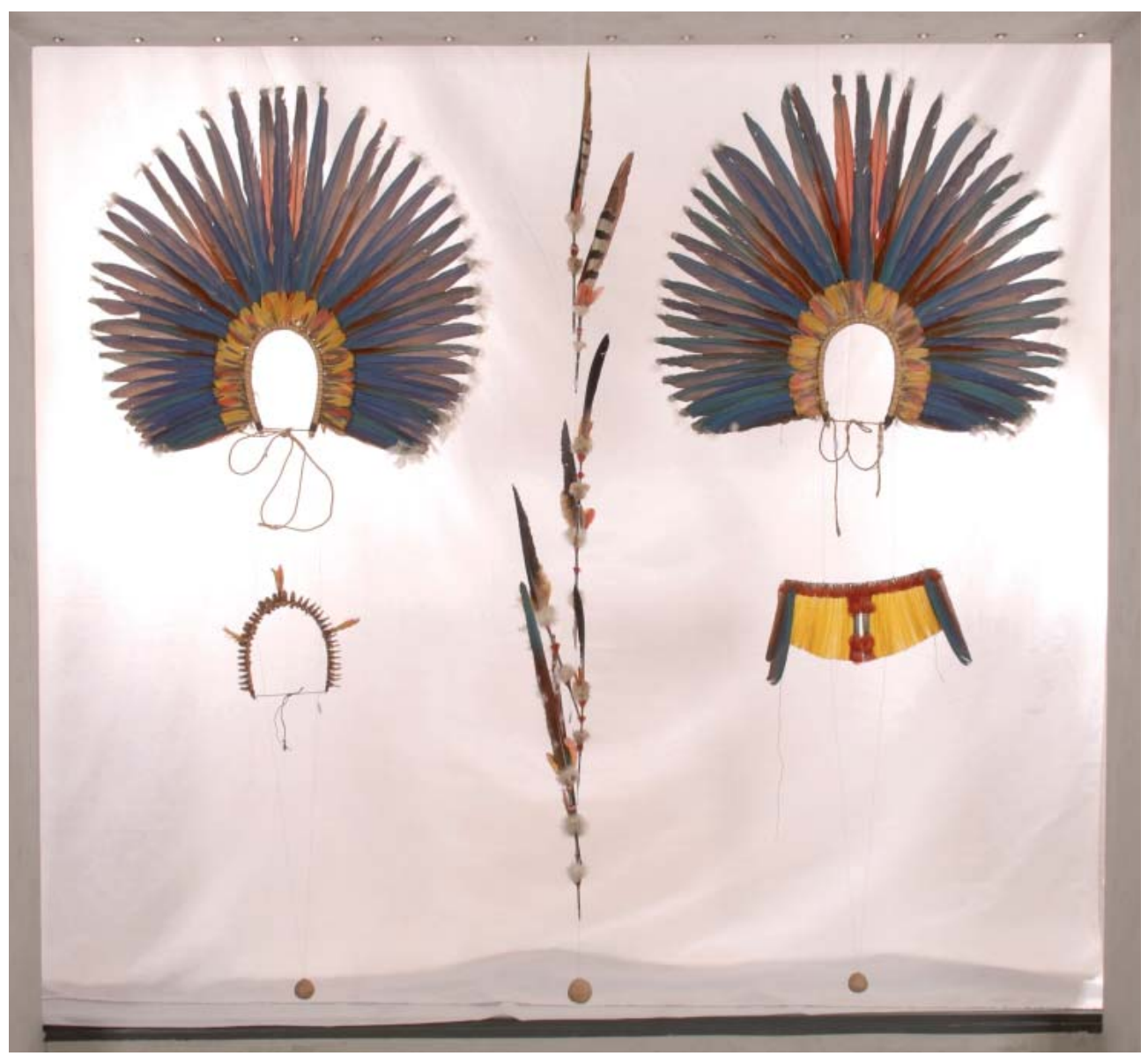

Figura 7 - Vitrine do clã Baadojebage Cobogiwuge (Metade Ecerae), durante a montagem 


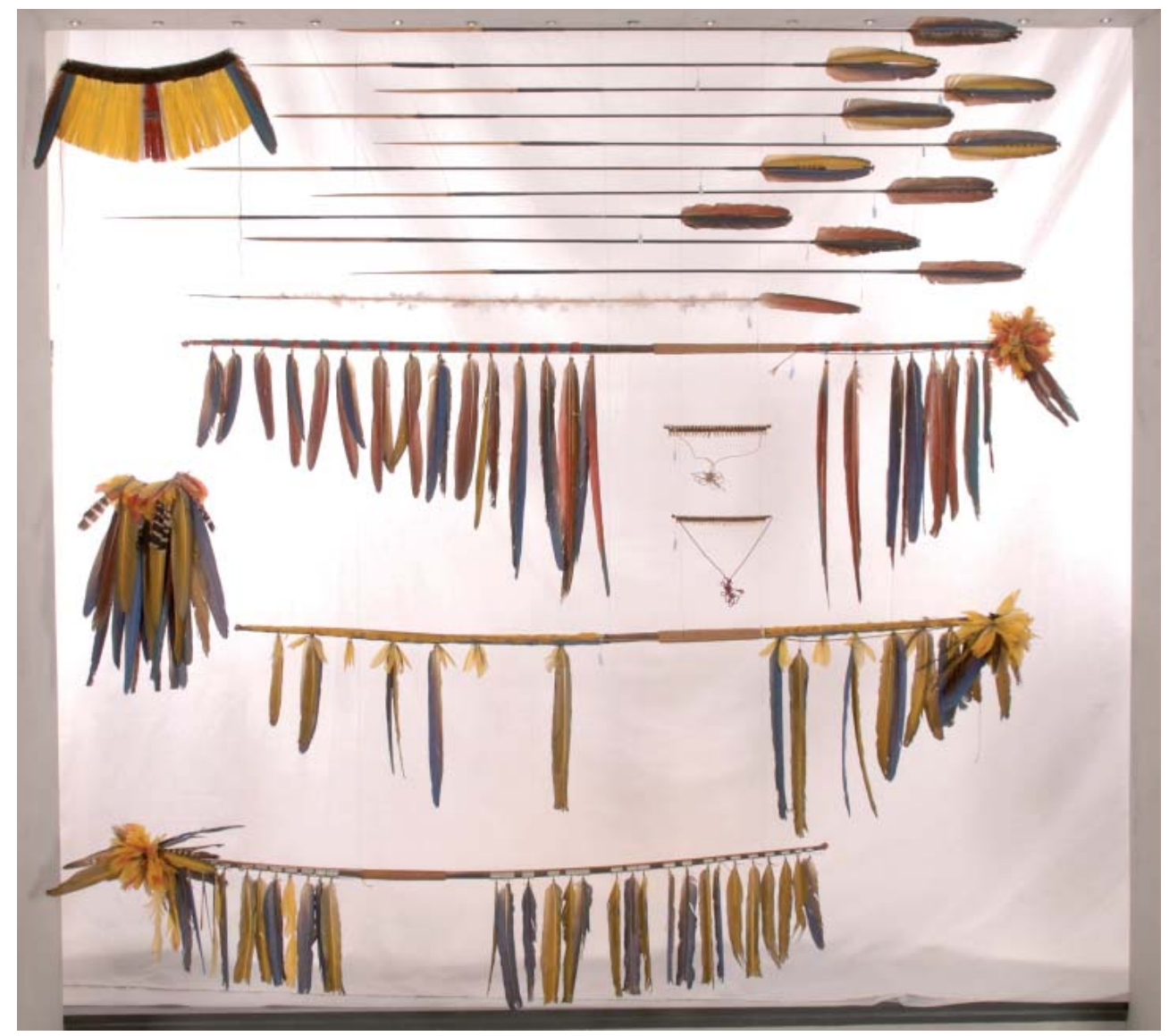

Figura 8 - Vitrine do clã Paiowe (Metade Tugarege), durante a montagem 


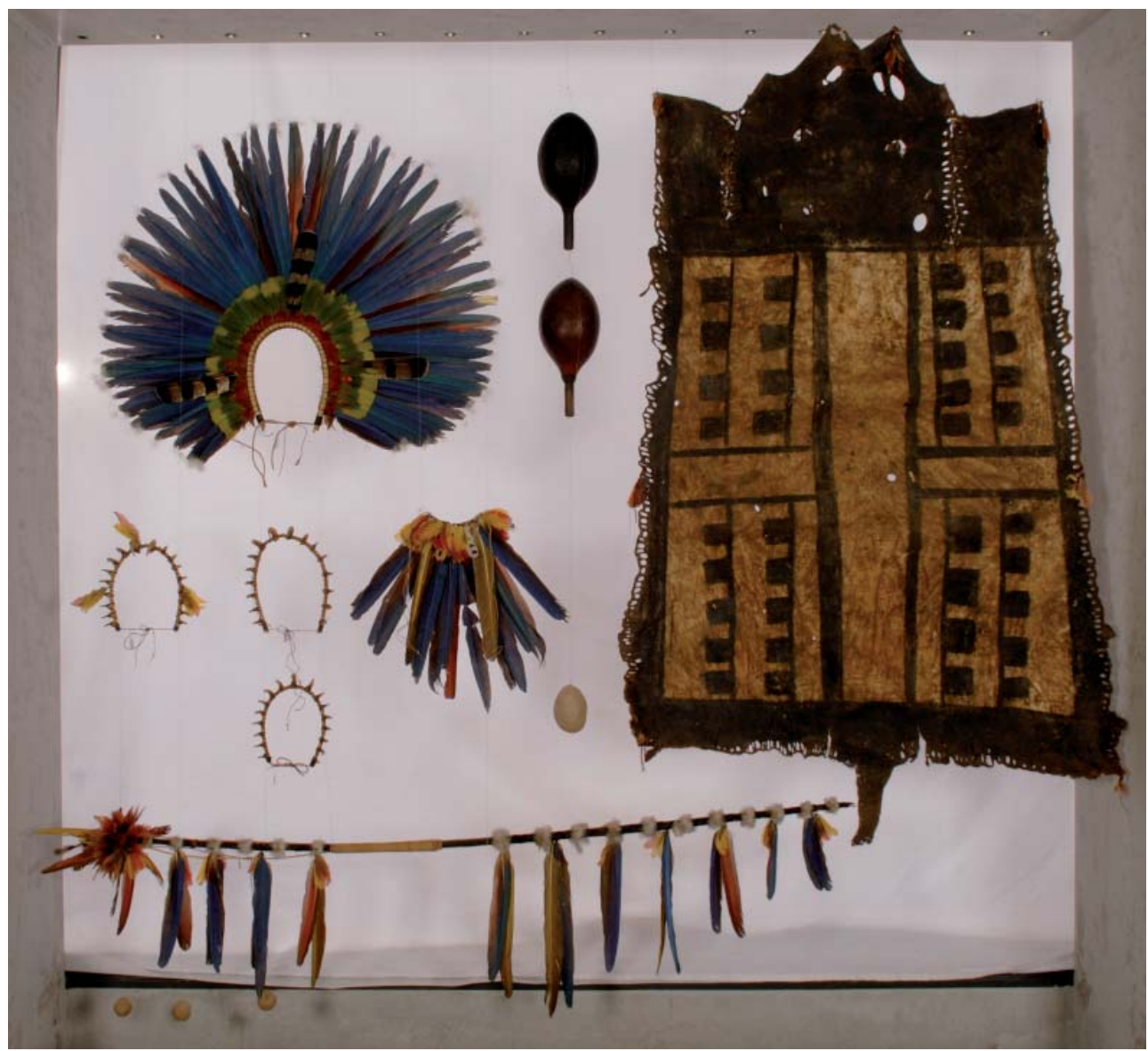

Figura 9 - Vitrine do clã Apiboregue (Metade Tugarege), durante a montagem 


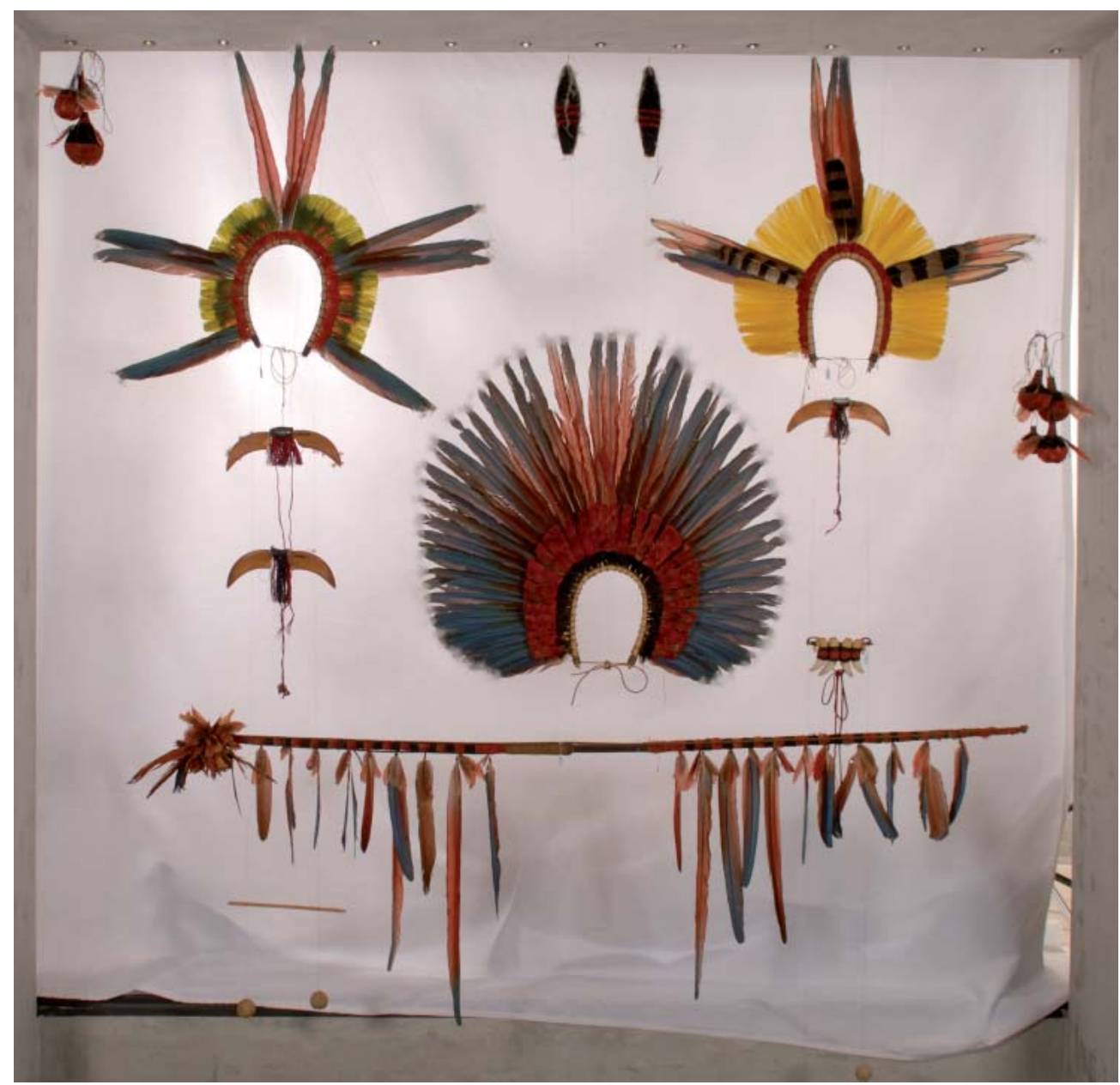

Figura 10 - Vitrine do clã Aroroe (Metade Tugarege), durante a montagem 


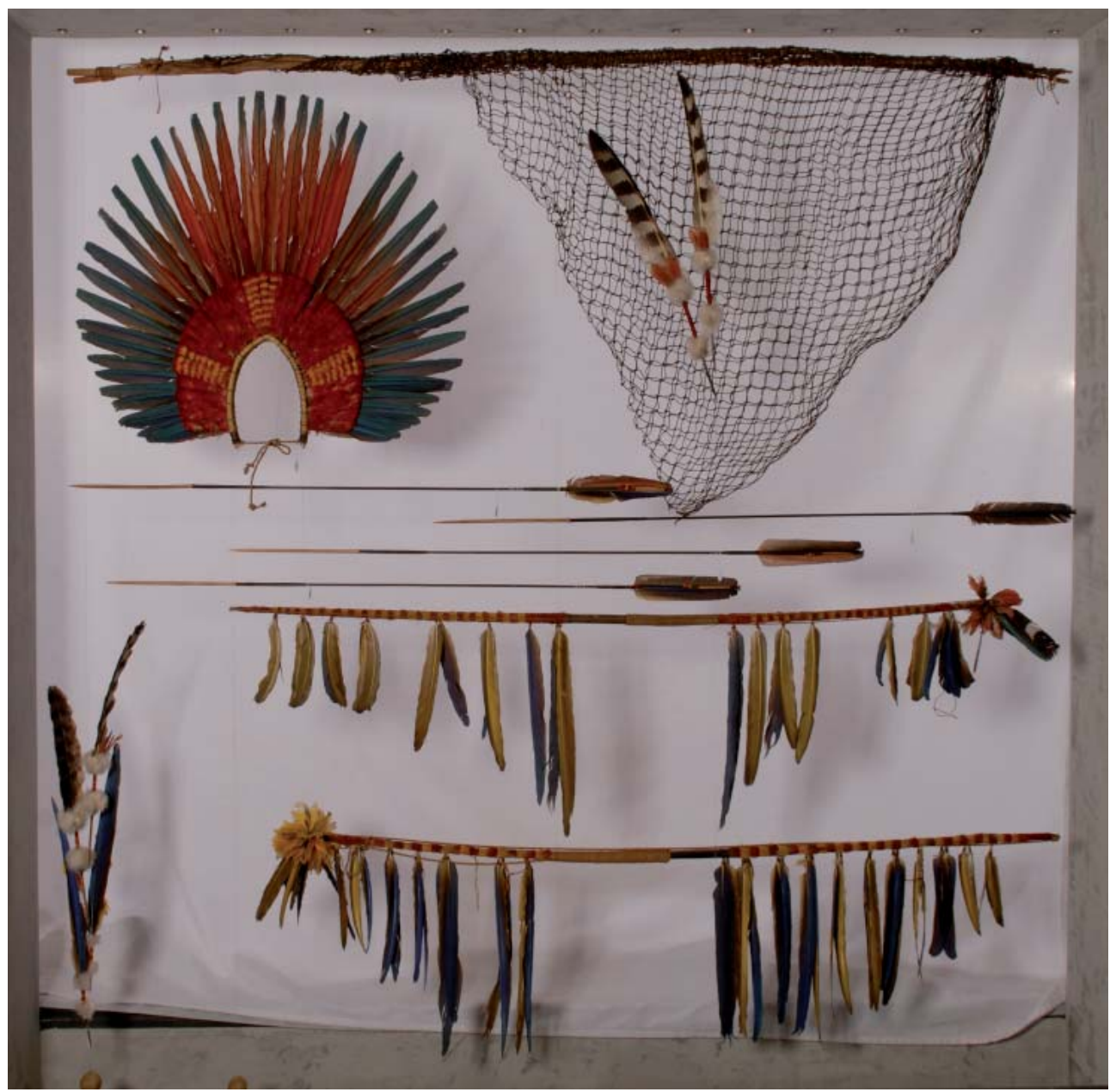

Figura 11 - Vitrine do clã Iwagududoge (Metade Tugarege), durante a montagem

Esse modelo atual busca apresentar elementos tradicionais da cultura bororo de forma que eles fiquem contextualizados e sejam privilegiados em suas especificidades. No modelo de exposição anterior do Museu, alguns tabus não eram respeitados, como o caso de algumas ossadas oriundas de rituais funerários, isso era motivo de reclamação por parte dos bororos. Reivindicação que não foi esquecida por aqueles que mais tarde participaram da desmontagem da exposição antiga e idealização do novo espaço. Quando o projeto da nova museografia foi proposto, a participação dos bororos determinou os objetos que ficariam em exposição, e mais ainda, à vista do visitante, de acordo com suas regras tradicionais. 
A mesma rigorosidade foi seguida na construção da exposição como um todo, visto que as leis que orientam a cosmologia bororo são estritamente rigorosas e claras. Qualquer desvio provoca um sentimento de desequilíbrio que não passa despercebido pelo grupo. Essa negociação constante entre equilíbrio e desequilíbrio orienta a vida dessa etnia, respeitar esse aspecto foi uma preocupação constante no processo de reestruturação e elemento motivador da participação dos indígenas na construção da exposição.

Com essa breve exposição, espero ter oferecido um suporte inicial às referências culturais presentes na Exposição Bororo do Museu das Culturas Dom Bosco. Ilustrei visualmente parte do repertório de objetos, referências e símbolos utilizados pelos bororos em seu cotidiano, ainda que nesse texto careçam essas informações.

Considero importante apontar novamente que toda a pesquisa artística que resultou nessa exposição foi desenvolvida em uma "curadoria compartilhada" que contou com a participação dos bororos na construção das estruturas e na disposição dos objetos, segundo primazia e relevância. Foram eles também que aconselharam o tratamento especial a objetos tabu contidos no acervo e que deveriam receber tratamento especial. Essa metodologia de trabalho também foi implementada no Museu das Culturas Dom Bosco com a exposição Xavante.

\section{Referências}

ALBISETTI, C.; VENTURELLI, A. J. Enciclopédia Bororo. Campo Grande, MS: MSMT, 1962. V. I.

VIERTLER, Renate Brigitte. A duras penas: um histórico das relações entre índios Bororo e "civilizados" no Mato Grosso. São Paulo: Faculdade de Filosofia Letras e Ciências Humanas da Universidade de São Paulo, 1990.

As aldeias Bororo: alguns aspectos da sua organização social. São Paulo: Museu Paulista, 1976. Série Etnologia, v. 2. 